\title{
The Investigation of Oxidative Stress-Related Parameters in Congenital Hypogonadism
}

\author{
Haymana $\mathbf{C}^{1}$, Aydogdu A $^{1}$, Soykut $\mathrm{B}^{2}$, Erdem $\mathrm{O}^{2}$, lbrahimov $\mathrm{T}^{1}$, Dinc $\mathbf{M}^{1}$, \\ Meric $\mathbf{C}^{\mathbf{1}}$, Taslipinar $\mathbf{A}^{\mathbf{1}}$, Basaran $\mathbf{Y}^{\mathbf{1}}$, Sonmez A'1, Azal $\mathbf{O}^{\mathbf{1}}$ \\ 1Department of Endocrinology and Metabolism, Gulhane School of Medicine, 06018 Etlik Ankara TURKEY
}

${ }^{2}$ Department of Pharmaceutical Toxicology, Gulhane School of Medicine, 06018 Etlik Ankara TURKEY

\section{OBJECTIVES}

Patients with hypogonadism are at increased risk of cardiac and metabolic diseases. The pathogenesis of increased cardiometabolic risk in hypogonadal patients is not clear. Oxidative stress plays an important role in the pathogenesis of cardio-metabolic diseases. The aim of this study was to search for any difference of the oxidative stress parameters between in patients with hypogonadism and healthy controls.

\section{METHODS}

Thirty eight male patients with congenital hypogonadotrophic hypogonadism $(\mathrm{CHH})$ (mean age 21.7 \pm 1.6 years) and 44 body mass index (BMI) matched healthy male subjects (mean age $22.3 \pm 1.4$ years) were enrolled. The demographic parameters, homeostatic model assessment of insulin resistance (HOMA-IR) and oxidative stress parameters such as superoxide dismutase (SOD), catalase, glutathione peroxidase (GPX) and malondialdehyde (MDA) were measured in patients and healthy controls.
Table-1: The demographic and metabolic parameters of the patien ts with CHH and the bealthy con trol subjects

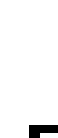

\begin{tabular}{|c|c|c|c|}
\hline & $\begin{array}{c}\text { Patients } \\
(\mathrm{n}=\mathbf{3}) \\
\text { (mennts.D. }\end{array}$ & $\begin{array}{l}\text { Healthy controls } \\
\qquad(n=34) \\
\text { (mean+s.D. }\end{array}$ & D. \\
\hline Ape $(6)$ & $21.7 \pm 1.6$ & $22.3 \pm 1.4$ & 0.11 \\
\hline BNII (leg/min) & $23.7 \pm 4.8$. & $24.9 \pm 27$ & 0.25 \\
\hline WC (cm) & Dg. $9 \pm 11.4$ & $86.8 \pm 63$ & 0.20 \\
\hline FBG (mg/dl) & $86.4 \pm 13.7$ & ga. $1 \pm 75$ & 0.58 \\
\hline LDL-C (mg/dD) & $9 \mathrm{ga}=25 \mathrm{~F}$ & $93.4 \pm 30.9$ & 0.52 \\
\hline HDL-C (mg/dD) & $42.2 \pm 11,7$ & $48.4 \pm 8.7$ & 0.04 \\
\hline Triplvcerides $\left(\mathrm{mg} / \mathrm{d} \mathrm{p}^{\mathrm{x}}\right.$ & 100.5 (80)7-193.0) & $82.0065-110.5)$ & 0.02 \\
\hline$\overline{\mathrm{L} H(\mathrm{~m} I \mathrm{~W} / \mathrm{mI})^{2}}$ & $0.1(0.07-1.32)$ & $3.909-4.9$ & $\infty 0.001$ \\
\hline FSH (NDW/mL) & $0.3(0.3-1.4)$ & $2.6(1.9-3.4)$ & $=0.001$ \\
\hline 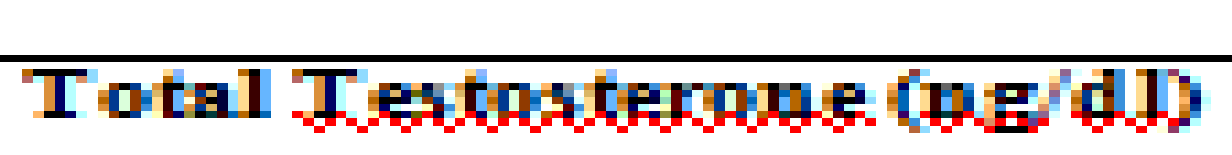 & $42.6 \pm 42.1$. & $503.2 \pm 1452$ & $\infty 0.001$ \\
\hline Insulin $(\mu \mathrm{IT} / \mathrm{ml})$ & $14.7 \pm 50$ & B. $6 \pm 32$ & $\approx 0.001$ \\
\hline HOMLA-IR & $3.1=13$ & $1.9 \pm 97$ & $=00.001$ \\
\hline $\operatorname{sOD}^{21}$ & 1133.7 (3)4. ㅇ-1697.9) & 962.1 (665/ 2000.5$)$ & 0.86 \\
\hline$\overline{C A T}$ & $717.2 \pm 17 \mathrm{AQ}$ & $566.6 \pm 1433$ & $\approx 0.001$ \\
\hline GPX & $51.04=6.9$ & $57.5 \pm 7.8$. & $\approx 0.001$ \\
\hline MIDA & $291.6 \pm 1977$ & $92.0 \pm 217$ & $\approx 0.0001$ \\
\hline
\end{tabular}

\section{CONCLUSIONS}

The results of this study show that young and treatment naïve patients with hypogonadism have increased oxidative stress related parameters such as serum catalase and MDA levels. There is significant correlation between oxidative stress parameters and testosterone levels. Prospective, randomized, controlled studies with larger number of cases are needed to prove the relationship between oxidative stress and increased cardiometabolic risk in hypogonadism.

\section{RESULTS}

When compared to the healthy controls, triglycerides $(p=0.02)$, insulin, HOMA-IR, catalase and MDA levels $(p=<0.001$ for all) were significantly higher, and the HDL cholesterol $(p=0.04)$, total testosterone, $\mathrm{FSH}, \mathrm{LH}$ and GPx levels $(p=<0.001$ for all) were significantly lower in patients with $\mathrm{CHH}$ (Table1). There were significant correlations between the total testosterone levels and catalase $(r=-0.33 p=0.01)$, GPx $(r=0.36 p=0.007)$ and MDA $(r=-0.47 p<0.001)$ levels.

\section{REFERENCES:}

1. Laaksonen DE, Niskanen L, Punnonen K, et al. Sex hormones, inflammation and the metabolic syndrome: a population-based study. Eur J Endocrinol 2003; 149: 601608.

2._Tangvarasittichai S. Oxidative stress, insulin resistance, dyslipidemia and type 2 diabetes mellitus. World $\mathrm{J}$ Diabetes 2015; 15: 456-480.

3. Sonmez A, Haymana C, Aydogdu A, Tapan S, et al. Enothelial dysfunction, insulin resistance, and inflammation in congenital hypogonadism and the effect of testosterone replacement Endocr J 2015; 62: 605-613. 